\title{
Liste sigles et abréviations utilisés dans ces textes
}

Acronyms and abreviations used in these texts

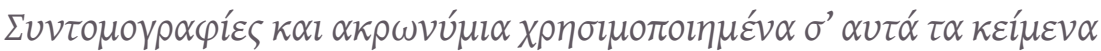

\section{OpenEdition}

\section{Journals}

Édition électronique

URL : https://journals.openedition.org/ceb/13568

DOI : $10.4000 /$ ceb. 13568

ISSN : 2261-4184

\section{Éditeur}

INALCO

\section{Édition imprimée}

ISBN : 978-2-85837-294-8

ISSN : 0290-7402

\section{Référence électronique}

"Liste sigles et abréviations utilisés dans ces textes », Cahiers balkaniques [En ligne], 45 | 2018, mis en ligne le 14 décembre 2018, consulté le 10 juillet 2021. URL : http://journals.openedition.org/ceb/13568 ; DOI : https://doi.org/10.4000/ceb.13568

Ce document a été généré automatiquement le 10 juillet 2021.

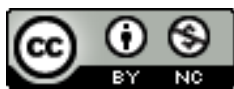

Cahiers balkaniques est mis à disposition selon les termes de la Licence Creative Commons Attribution - Pas d'Utilisation Commerciale 4.0 International. 


\title{
Liste sigles et abréviations utilisés dans ces textes
}

\author{
Acronyms and abreviations used in these texts

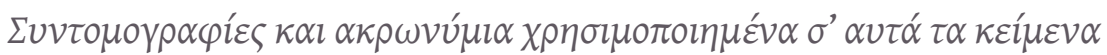

AKP : Adalet ve Kalkınma Partisi, Parti de la Justice et du Développpement.

BIT : Bureau international du Travail.

3 CITI : Classification internationale Type par Industries

4 CITP : Classification internationale par type de professions.

$5 \quad$ CPA : Classification des Produits Associés aux activités UE.

6 CPC : Central Cassification of Products, Classification centrale des Produits ONU.

7 DİSK : Türkiye Devrimci Isşçi Sendikaları Konfederasyonu, Confédération des syndicats révolutionnaires de Turquie.

DTO : Deniz Ticareti Odası, Chambre de Commerce maritime.

9 EFIM : Ente partecipazioni e finanziamento industrie manifatturiere, Organisme public de participation et de financement de l'industrie manufacturière.

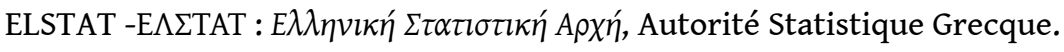

ENEL : Ente nazionale per l'energia elettrica, Organisme public pour l'énergie électrique.

ENI : Ente Nazionale Idrocarburi, Organisme public des Hydrocarbures.

ESP : Ezilenlerin Sosyalist Partisi, Parti socialiste des opprimés.

14 FMN : Firme multi-nationale.

15 GDP -PIB : Gross Domestic Product, Produit Intérieur Brut.

GISBIR : Gemi İnşa Sanayicileri Birliği, Union des Industriels de la Construction navale.

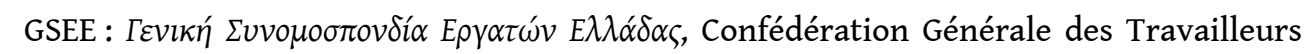
de Grèce.

HAK-İş Konfederasyonu : Confédération des droits des travailleurs.

IIS : Institut international de la Statistique. 
INSEE : Institut national de la Statistique et des Études Économiques.

IPEMED : Institut de prospective économique du monde méditerranéen.

IRI : Istituto per la Ricostruzione Industriale, Institut pour la Reconstruction Industrielle.

ISCO: International Standard Classification of Occupations = CITP : Classification international standard des professions.

ISI : Industrialisation par Substitution d'Importations (Turquie).

ISIC : International Standard Industrial Classification, Classification international standard des industries

ISIS (CITI en français): International Standard Industrial system, Système industriel internationale standard.

KAMU-SEN : Türkiye Kamu Çalışanları Sendikaları Konfederasyonu, Confédération des Travailleurs du secteur public de Turquie.

KESK : Kamu Emekçileri Sendikası Konfederasyonu, Confédération syndicale des employés du secteur public (Turquie).

KOSGEB : Küçük ve Orta Ölçekli İşletmeleri Geliştirme ve Destekleme İdaresi Başkanliğ, Organisation pour le développement des petites et moyennes entreprises (Turquie).

$\mathrm{MCN}$ : Machines à commande numérique.

MEMUR-Sen: Memur Sendikaları Konfederasyonu, Confédération des syndicats des Employés (Turquie).

MSHA : Maison des Sciences de l'Homme d'Aquitaine.

MÜSIAD : Müstakil Sanayici ve İşadamları Derneği, Association d'industriels et d'hommes d'affaires indépendants (Turquie).

NACE : Nomenclature des Activités dans la Communauté Européenne

OCEMN : Organisation de Coopération économique de la mer Noire fondée en 1992 à Istanbul.

PIB : Produit Intérieur Brut.

PATHE : Patras-Athènes-THEssalonique.

PME : Petites et moyennes entreprises.

Prodcom : Productions communautaires.

SDN : Société Des Nations.

SHS : Sciences Humaines et Sociales.

SMEs : Small and medium-sized enterprises, Petites et moyennes entreprises.

SOEs : State Owned Enterprises, Entreprises d'État.

SSE : Système Statistique Européen.

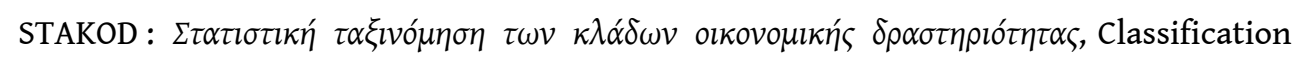
statistique des secteurs d'activité économique.

STP : Software Test Professionals, Professionnels des tests logiciels.

TACIS : Technical Assistance to the Commonwealth of Independant States-CEI, programme créé en décembre 1991.

TER : Tableau Emploi Ressources. 

international né en 1993 impliquant l'Union européenne et quatorze États membres de l'Est européen, du Caucase et de l'Asie centrale (Arménie, Azerbaïdjan, Bulgarie, Géorgie, Kazakhstan, Kirghizistan, Iran, Moldavie, Ouzbékistan, Roumanie)

51 Türk-İş: Türkiye İşçi Sendikaları Konfederasyonu, Confédération des syndicats de travailleurs turcs.

TÜSİAD : Türk Sanayicileri ve İşadamları Derneği, Association des industriels et des entrepreneurs de Turquie.

$53 \quad$ TVA : Taxe à la Valeur Ajoutée.

54 UE : Union Européenne.

55 VA : Valeur Ajoutée. 